\title{
The Public Understanding of Science Matters
}

\begin{abstract}
The 1996 Cecil Powell Memorial Lecture The Public Understanding of Science - the British Experience was presented at the 10th EPS General Conference (Seville; 9-13 September 1996) by Sir Arnold Wolfendale, President of the Institute of Physics and the 14th Astronomer Royal.
\end{abstract}

Some of the measures developed in the last October's report Public Understanding of Science, Engineering and Technology published by the UK's ministerial Office of Science and Technology have started to take effect. However, those relating to the formal responsibility of scientists and engineers for promoting public understanding and the ways in which their efforts should be recognized will take longer to formulate.

There has been general agreement among scientists and engineers for some years that the public understanding of science matters for many reasons. Science contributes to economic wealth. In other words, it is to a country's advantage to have more people understanding and working in science provided that there are adequate jobs for them. It also strengthens the effectiveness of the democratic process. In other words, we all need to know quite a bit about science so that we can help make some of the great decisions of the age. Of course everybody is important, but the report of the ad hoc committee established by the UK's minister for science called Public Understanding of Science, Engineering and Technology highlighted the importance of so-called gatekeepers in the media and not just politicians and policy formers. It is they who decide whether editors should tell the public about something. In the UK there has been a conscious effort to convince these people - who are almost entirely arts graduates - of the importance of science.

The term understanding is in fact a misnomer for anyone who has sat through a technical lecture will know that even a specialist's understanding is not always very great. Much of science is very technical. Indeed at the cutting edge, few really "understand". The public needs to be "aware" of science - to have an "appreciation" of science and its contribution to national life. These are better terms. In the UK there has also been an effort recently which is proving successful to increase the scope of so-called science by including engineering and technology.

Concerning the British experience, one can start with the mid-1980s when the Royal Society published an influential report on the public understanding of science prepared by an ad hoc group chaired by Sir Walter Bodner, the distinguished biologist. As one might perhaps expect, an important outcome was the creation of another committee. This committee - the Committee on the Public Understanding of Science (COPUS) - was established by the Royal Society, the Royal Institution and the British Society for the Advancement of Science. It exists to this day and still makes an outstanding contribution.

In 1992, the newly elected government declared its commitment to the promotion of the public appreciation and understanding of science, engineering and technology. A minister for science was appointed and a White Paper Realising Our Potential published in 1993 has had a significant effect on the organization of science in Britain. Included for the first time in a government White Paper was a strategy for raising the public awareness of the contribution of science, technology and engineering to national wealth and well-being. In the following year, the Competitiveness White Paper noted the need to enhance the understanding and status of engineering at the board level and among financial institutions and opinion formers.

An ad hoc committee chaired by Sir Arnold Wolfendale was formed in January 1995 and asked to look into a particular aspect of the public understanding of science, namely the idea that particularly in universities and other institutions of

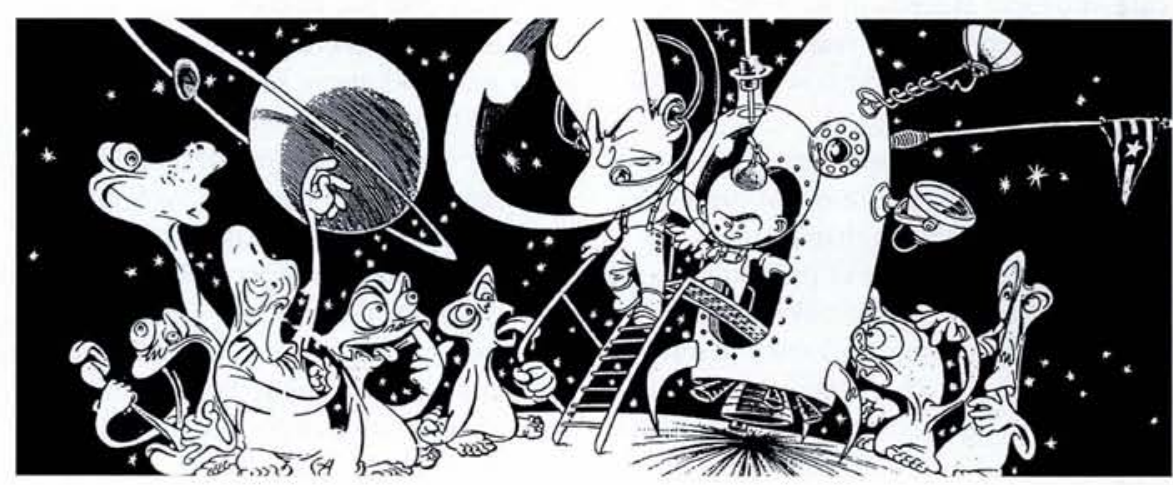

higher education, ".... scientists engineers and research student in receipt of public funds have a duty to explain their work to the public". The words are taken from the committee's report Public Understanding of Science Technology and Engineering which was published in October 1995 by the research minister's Office for Science and Technology (OST).

The idea that research students should help promote science is very praiseworthy, but one can see the hazards. Imagine a research student going to a woman's institute and lecturing on quantum chromodynamics, for example. Such initiatives could do irreparable damage to science over a wide area. So the committee of nine was asked to ".... review the steps currently being taken to equip and encourage professional scientists, engineers and research students to contribute to improved public understanding of science, engineering and technology and to suggest how these might be improved ....."

The committee first undertook a wide-ranging consultation to establish what was already being done. Some 36 universities then received a consultation document based on the first-round's findings since it was clear that the university system as a whole could enhance its contribution. The committee also interviewed a number of "practitioners" in the field of public understanding.

\section{Two Vital Aspects}

Two aspects seemed to be very important, especially for universities and those engaged in basic research. First, concerning public attitudes to universities, many people still think that universities are ivory towers with little relationship with the outside world. It is important to break down such important barriers, most of which are imaginary. For imagination is perhaps more important than the reality as it is what people think which is crucial.

Second, the UK government, like many others, is obsessed with wealth crea- 
tion and much of what basic science does should lead to an increase in wealth. The public understanding of science affects the perception of the need for basic research in many countries. Basic research is at risk because of this obsession with shorttermism and wealth creation. This perhaps explains why a UK newspaper chose to give Sir Arnold's summary of his committee's report the interesting title "Explain or die: why science can't afford to keep secrets from the people". One may laugh, and Cecil Powell would probably have done so. But such headlines are important since they stress the fact that people are paying for what scientists are doing, and it is the scientists' job to tell the public about their work.

Big science, more accurately the "most basic science" epitomised by particle physics and astronomy, is in peril. In "big" physics such as astronomy, it was thought that the end of the cold war would bring a peace dividend. But governments now question the need for developing space vehicles which provided facilities for scientists; there is not the same urgency so there has been some reduction in support. In particle physics, the argument is that since there is no Superconducting Super Collider anymore, what is the rush to support CERN. The Higgs can wait. It has waited a long time; it can wait a bit longer. This is a very serious problem. Then there are the many new areas of science springing up that need funding. If practitioners can get out there and tell the public what it is all about one hopes that the situation may improve, or at least not get any worse.

Small physics in UK has also been under considerable threat, partly because of organizational aspects (it is now not handled by the same research council as astronomy and particle physics) but also because it is perceived as being remote from wealth creation. What nonsense one may say. Nevertheless, one must get across the importance of science, whether it be very large or very small.

\section{Progress in Some Areas}

The report's recommendations started with general statements that the public understanding of science, engineering and technology should be encouraged, and that university initiatives to equip staff and students varied considerably. There was scope for improvement, especially in the area of communication skills.

Some of the report's recommendations have already being tackled in the context of new government initiatives. This is the case, for instance, with the teaching of science and technology in schools, which has problems and remains a continuing source of concern. Many of those interviewed were absolutely right when they said that one must start in the schools.

Research councils (the UK has two for physics) were urged to develop further their grant procedures to make public understanding an integral part. Every grant applicant should include a statement describing how public understanding would be improved, and after a grant is finished, each should say what had been done. The problem is of course to know how much notice would be taken. But something is happening. For example, the council for astronomy and particle physics now lets grant holders spend $1 \%$ of a grant for this activity. This may not sound much, but $1 \%$ of $200 \mathrm{M} £$ per annum is a large sum. There clearly have been improvements and one can be reasonably happy.

Regarding communication skills.

Time and again one hears that people cannot communicate, although the criticism is somewhat less than before for science graduates. It is said, for instance, that most graduates may have good science, but they cannot tell others people about science. The report stressed the need to impart communication skills at all stages in universities. Simple things such as preparing readable transparencies can be taught, and should be taught. One was probably preaching to the converted since communication skills are being taught to university students and to some extent in schools. Nonetheless, it does no harm to stress them because they are crucial for all walks of life.

The report recommended that funding bodies should ensure a continuing role for adult education in promoting the public understanding of science. People in adult education have been having a difficult time recently in the UK, but funding agencies should face the fact that there are after all professionals whose job it was to endeavour to let us say "educate" the public. The committee also felt that other existing bodies and structures could do more. For instance, the COPUS committee should be expanded to include engineering, professional institutes such as the Institute of Physics should be more active in the area of public understanding, the OST should commission a Best Practice Guide and study the present status of the public understanding of science, and the universities should develop cost-effective ways of measuring performance in public understanding. Sir Arnold's committee had in mind subjective measures of quality based on questionnaires and audience interviews, in addition to some obvious and simple quantitative measures such as the time spent and a log of events categorised according to audience type and size.

\section{Some Debate Remains}

There is a difference in opinion within the science and engineering community about the report's statement that scientists, engineers and research students have a "duty" to be involved in promoting public understanding. The term duty was used advisedly because it was not meant to imply a legal obligation. Individuals have to do what they think fit, although for basic science the simple view was perhaps the best. Basic scientists receive taxpayers' support to pursue their interests so they have a duty to tell the public something about their work.

Equally contentious was the report's view that the increased responsibility of academics and others for educating the public should lead to more recognition for the individual. For example, in choosing between grant applications of equal merit one should select the person who will do more to popularise science. A similar situation arises for undergraduates. As the committee's report puts it: "Institutions may wish to consider whether it would increase recognition by students of the importance of communication skills if the successful completion of communication skills courses by undergraduates were to count in the final degree mark."

Promoting the public understanding of science is clearly a necessary activity for all scientists. An individual's response to the challenge will of course depend on that individual. Sir Arnold's advice was that one should lecture on exciting topics and not be afraid to talk about subjects outside one's speciality, even if it means that the media may try to add to the discomfort. He recalled the occasion when a major UK newspaper chose to accompany a very straightforward item he wrote on the search for extraterrestial life with a rather malicious cartoon! For the essential point is that physicists should keep in mind the need for audience participation and a liberal dose of humour. Cecil Powell, after all, remarked that a noose of rope seen dangling above the head of Victor Hess in a photograph taken just before his epochmaking balloon flight in which he discovered cosmic rays would perhaps have been used if he had not made the discovery. 